\title{
The Near-Death Experience: A Study of Its Validity
}

\author{
Aureliano Pacciolla, Ph.D. \\ Catholic University Marianum, Augustinianum, and \\ Regina Mundi, Rome, Italy
}

ABSTRACT: An Italian translation of Greyson's (1983a) NDE Scale was administered to 125 individuals who had been resuscitated at a hospital in Italy. By NDE Scale criteria 37.5 percent of those who returned the questionnaire had authentic NDEs. These data suggest some limitations to Greyson's NDE Scale and recommendations for future research.

The purpose of this article is to verify the frequency of near-death experiences (NDEs) among those who come close to death, using what is proposed to be the most appropriate scale, and to show the correlations of the contents of NDEs among those who report undergoing such phenomena. An NDE may be best defined as the experience of those

people who have been seriously injured or ill but unexpectedly recovered and by people who had anticipated imminent death in potentially fatal situations but escaped uninjured. (Greyson and Stevenson, 1980, p. 1193)

Aureliano Pacciolla, Ph.D., is Assistant Professor of Psychology and Moral Theology at the Catholic University Marianum, Augustinianum, and Regina Mundi in Rome, teaches hypnosis at the postgraduate Centro Italiano Ipnosi Clinica Sperimentale (C.I.I.C.S.) in Turin, and practices as a clinical psychologist with adolescents at the Scuola di Discussione in Corridonia. This paper is based on a degree thesis by Dr. Enrica Zampieri entitled "L'Esperienza di Pre-Morte: Un'applicazione Statistica in Italia della NDE Scale," submitted in 1990 to the Faculty of Education at the University of Padua for the Degree Course in Psychology. Thesis examiners were Prof. Carlo Semenza and Prof. Aureliano Pacciolla. Reprint requests should be addressed to Dr. Pacciolla at the Centro Internazionale S. Alberto-Carmelitani, Via Sforza Pallavicini, No. 10, 00193 Rome, Italy. 
In order to understand what the NDE implies, we should take into consideration that the research indicates that NDEs "include strong positive affect, dissociation from the physical body, and transcendental or mystical elements" (Greyson, 1983a, p. 369), more specifically

a conviction that one did indeed die; an impression of being outside the physical body; an impression of passing through a dark, enclosed space; apparent extrasensory phenomena; apparent encounters with persons not physically present; an impression of entering some unearthly realm of existence; and a review of past events, or "panoramic memory." (Greyson, 1983b, p. 376)

\section{The Study}

The objectives of the study were to draw attention to the percentage of subjects who recall a near-death experience, to present the contents of NDEs in the cases under study, and to check the reliability of a particular method of studying NDEs. The contents of NDEs were assessed by the NDE Scale developed by Bruce Greyson (1980a). This scale is considered the most reliable method of studying NDEs to date, given the various changes which resulted from the scientific tests carried out to validate the method.

\section{Subjects}

Each of the 125 proposed subjects in this study had one or more experiences of recovery in a resuscitation department. The circumstances of their coming close to death were varied, including cardiac arrest, cerebral hemorrhage and other strokes, head trauma, various forms of poisoning, anaphyllactic shock, postoperative complications, eclampsia, tetanus, serious respiratory insufficiency, and comas of varous etiologies.

Of the 125 proposed subjects, 71 were male ( 56.8 percent) and 54 were female (43.2 percent); they were of a mixture of ages and social backgrounds.

\section{Procedure}

This study was conducted from May, 1989, to February, 1990, in the resuscitation department of the Hospital U.S.S.I. (Unita Sanitaria Locale) 61 in Savigliano (CU), Italy. It was the object of a degree 
thesis by Enrica Zampieri at the University of Padua, under the supervision of Carlo Semenza and Aureliano Pacciolla.

Questionnaires were mailed to subjects with a prepaid return envelope. The questionnaire included an open-ended question inquiring about the nature of the experience, as well as Greyson's (1983a) NDE Scale, an instrument that has been shown to have high internal consistency, split-half reliability, test-retest reliability, high correlation with Kenneth Ring's (1980) Weighted Core Experience Index (WCEI), and a capacity to differentiate between authentic NDEs and organic mental syndromes or nonspecific stress reactons. The NDE Scale is made up of 16 questions with 3 possible responses each; a response definitively indicating the presence of an NDE element is awarded 2 points, an ambiguous response indicating the possible presence of an NDE element is awarded 1 point, and a negative response indicating the absence of that NDE element is awarded 0 points. Subjects who score a total of 7 or more points out of a possible 32 are considered to have had an authentic NDE.

The NDE Scale is divided into four sections to bring out the four essential components of NDE: the cognitive component, which highlights an accelerated perception of time and of one's own thoughts, the remembering of one's past (with a panoramic view of one's life), and an understanding of one's self and of the world; the affective component, which focuses on the sensations of peace, harmony, joy, and light, sensations that are often described as extremely pleasant; the paranormal component, which deals with the sensation of being separate from one's own body, and with the capacity to foresee the future and to experience events happening in other places; and the transcendental component, which has to do with the sensation of having met other persons or "beings" in places other than the usual ones, and with the ways in which subjects "return to life."

\section{Results}

Of the 125 subjects to whom questionnaires were sent, $64(51.2$ percent) completed the questionnaire. Of the 61 potential subjects who did not return the questionnaire, 32 had died.

The average age of the 64 respondents was 44.4 years. Of those 64 respondents, 38 were male (59.4 percent) and 26 were female (40.6 percent). All of them declared themselves to be Roman Catholic (as do 95 percent of the population of Italy). Respondents described 


\section{Table 1}

\section{Percent of Definitive, Ambiguous, and Negative \\ Responses to Cognitive and Transcendental \\ Component Questions}

\begin{tabular}{lcc}
\hline & $\begin{array}{c}\text { Cognitive } \\
\text { Component }\end{array}$ & $\begin{array}{c}\text { Transcendental } \\
\text { Component }\end{array}$ \\
\hline $\begin{array}{l}\text { Definitive response } \\
\text { (indicating NDE element) }\end{array}$ & $11 \%$ & $23 \%$ \\
$\begin{array}{l}\text { Ambiguous response } \\
\text { (indicating possible NDE element) }\end{array}$ & $28 \%$ & $33 \%$ \\
$\begin{array}{l}\text { Negative response } \\
\text { (indicating no NDE element) }\end{array}$ & $61 \%$ & $44 \%$ \\
\hline
\end{tabular}

NDEs that had occurred over a period from 3 months to 10 years previous to the questionnaire. There were no significant statistical correlations between the sex of the persons studied and the medical circumstances of the close brush with death, and NDEs.

Of the 64 subjects who completed the NDE Scale, 24 (13 male and 11 female) had a score of 7 or more; that is 37.5 percent of respondents who had come close to death had an authentic NDE, according to Greyson's criterion. In the open-ended question, those who had a score of 7 or more (unlike those with a score of less than 7) described their experience as "an emotionally intense experience."

Among the four components of the NDE, the highest average score was found in the transcendental component, while the lowest was in cognitive component, as indicated in Table 1.

Although the four questions measuring the cognitive component collectively had the fewest number of positive responses, item 3 , addressing the review, was answered positively by 50 percent of respondents: 42 percent remembered many past events during the experience (the ambiguous response), and an additional 8 percent had their past flash before them, totally beyond their control (the definitive response).

The questions that received the greatest percentage of definitive positive responses were item 8 , seeing or feeling surrounded by a brilliant light, and item 16, coming to a border or point of no return. For item 8, 46 percent reported a light clearly of mystical or otherworldly origin, and an additional 12 percent reported an unusually 
bright light. For item 16, 46 percent described a barrier they were not permitted to cross, or being "sent back" to life involuntarily, and an additional 12 percent reported a conscious decision to "return" to life.

The questions that received the greatest percentage of negative responses were item 1, time distortion, and item 10, ESP during the NDE. For each of these two items, 71 percent of respondents reported no such experience.

On the other hand, the questions that received the lowest percentage of negative answers were item 5 , a feeling of peace or pleasantness, and item 14, seeming to encounter a mystical being or presence.

\section{Discussion}

The results of this study seem to confirm that the NDE is not dependent on personal or demographic factors. The person's gender, age (either at the time of resuscitation or of the study), socioeconomic status, and the conditions and causes of the crises that precipitated the experience are independent variables with respect to both the occurrence and contents of NDE.

Furthermore, according to this study, on the basis of the NDE Scale 37.5 percent of those who answered the questionnaire can be regarded as having had an authentic NDE. This estimate comes close to the 41 percent found by Michael Sabom in his research (1982).

The most important limits of the present research are those inherent in the small number of subjects and in the brevity of the questionnaire: only 16 questions, each with 3 possible responses, and one open-ended question. Other limits of this study, and indeed of most near-death research, are the absence of a specific psychodiagnosis and of personality tests both before and after NDE. Moreover, it cannot be deduced from this study that the NDE is independent of religious belief because, as already indicated, all the subjects declared themselves Roman Catholic.

In future studies, it would be interesting to clarify why it is that not all those who come critically close to death go through or remember an NDE. Research is needed to test the hypothesis of a difference in psychic structure between those who do and those who do not recall an NDE in connection with their experience of being close to death. Further clarification might also come from studies of groups 
where members are of different religious beliefs, but have similar pathology and/or have been administered the same drugs.

\section{Conclusion}

In regard to its initial objectives, the present study has reached certain conclusions:

First, not all of those who have been close to death report an NDE; the proportion who do is $\mathbf{3 7 . 5}$ percent.

Second, it can be confirmed that the experience and contents of NDE retain a certain similarity despite differences of age, sex, socioeconomic conditions, and the cause of the near death experience.

Third, the contents of the NDE are those foreseen in the four subdivisions in Greyson's NDE Scale. However, the least characteristic component in this study was the cognitive one, and the least characteristic phenomena were time distortion and telepathy.

The most characteristic component of the NDE in this study was the transcendental, and the most characteristic phenomena were a particularly bright light from some mystical source, and the sensation of coming to some boundary or barrier preventing the person from going any further or a conscious decision to come back into life. Two other experiences particularly typical of NDEs were the sensation of well-being and a sense of being in a mystical unfamiliar place.

We cannot exclude the possibility of other characteristic phenomena of the NDE not foreseen in Greyson's NDE Scale. Indeed, undoubtedly there are others that may be difficult to verify because they happen after the NDE, as in the case of changes in lifestyle and values, the acquisition of paranormal capacities, and the development of new levels of sensitivity, such as a heightened sense of hearing or smell.

And finally, the reliability of the means of investigating NDEs has to be regarded as still inadequate. The data from this study suggest that Greyson's NDE Scale should be modified, especially in regard to the cognitive element, and should be extended. If Greyson's NDE Scale, which is the most widely supported questionnaire in scientific circles, is to be regarded as not yet sufficiently reliable, the results of other questionnaires that do not have the scientific support of his clearly cannot be regarded as sufficiently reliable. 


\section{References}

Greyson, B. (1983a). The Near-Death Experience Scale: Construction, reliability, and validity. Journal of Nervous and Mental Disease, 171, 369-375.

Greyson, B. (1983b). The psychodynamics of near-death experiences. Journal of Nervous and Mental Disease, 171, 376-381.

Greyson, B., and Stevenson, I. (1980). The phenomenology of near-death experiences. American Journal of Psychiatry, 137, 1193-1196.

Ring, K. (1980). Life at death: A scientific investigation of the near-death experience. New York, NY: Coward, McCann and Geoghegan.

Sabom, M. B. (1982). Recollections of death: A medical investigation. New York, NY: Harper and Row. 